\title{
10
}

\section{O SILENCIO DO ESTRANGEIRO \\ POR UMA TENTATIVA DA TRADUÇÃO DA LETRA NOS PRIMEIROS CADERNOS DE ALBERT CAMUS}

Raphael Luiz de Araújo ${ }^{1}$

Samara Fernanda A. O. de Lócio e Silva Geske²

RESUMO: Partindo das teorias de Antoine Berman em A prova do estrangeiro, o presente artigo tem como objetivo introduzir uma discussão acerca da tradução dos primeiros cadernos de Albert Camus. A proposta de uma tradução da letra do original permite que se conserve a natureza própria dos cadernos que é de ser fragmentário, íntimo e inacabado, evitando, assim, processos como o de clarificação e o de enobrecimento. Essa postura tradutória se coaduna com a temática camusiana do silêncio e do estranhamento, que podemos observar ao longo de toda sua obra, e particularmente nos cadernos.

PALAVRAS-CHAVE: tradução; cadernos; silêncio, Albert Camus; Antoine Berman
ABSTRACT: From Antoine Berman's theories in L'épreuve de l'étranger, this article aims to introduce a discussion about the translation of Albert Camus' first notebooks. The proposal of a translation from the letter of the manuscript allows maintaining the proper nature of the notebooks that is the feature to be fragmented, innermost and unfinished avoiding the some processes such as the clarification and the ennoblement. This manner of translate combines the camusian themes of the silence and the estrangement which we can observe through his whole work and particularly in the notebooks.

KEY-WORDS: translation; notebooks; silence; Albert Camus; Antoine Berman

\section{1. "ESCREVER MINHA ALEGRIA PROFUndA": TRADUÇÃO E HETEROGENEIDADE NOS CARNETS}

Considerando que aventurar-se em uma operação tradutória compreende submeter-se a um trabalho de intermediação entre duas culturas a partir de um objetivo ideológico, no presente artigo é proposta uma possibilidade de tradução para o português brasileiro dos cadernos do escritor argelino Albert Camus (1913-1960) sob uma abordagem que defende tal processo enquanto “(...) um gesto de abandono do mesmo, do conhecido, a ida de encontro ao outro, que resultaria em um espaço de mestiçagem no qual seriam valorizadas as especificidades e diferenças das culturas e das línguas de cada povo". (Chanut, 2012, p. 164). Para se inserir no espaço silencioso e íntimo dos cadernos de forma ética a tradução transforma-se não somente em gesto técnico, mas em movimento crítico que ultrapassa o julgamento de valor sobre a obra e reflete sobre a experiência que resultou a sua criação.

Dos vinte e dois anos até a sua morte, Camus deixou anotações em nove pequenos cadernos escolares de folhas quadriculadas. Tais escritos são de cunho diverso, abrangendo notas de leitura, relatos cotidianos, diários de viagens, projetos de obras, gênese de textos que

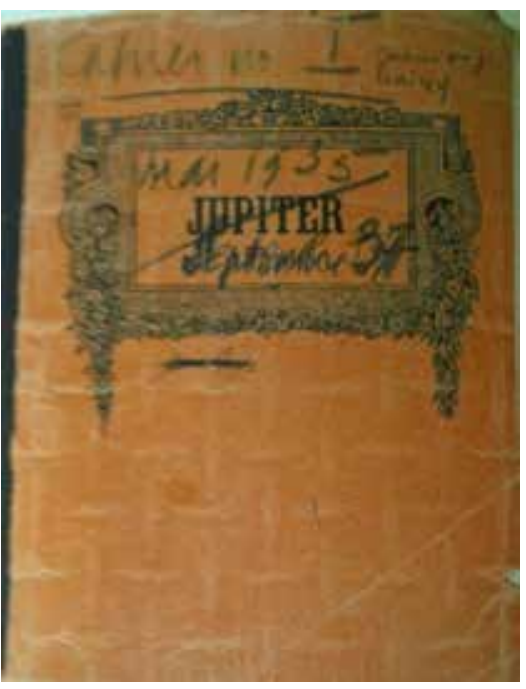

1 Mestrando em literatura francesa junto ao Departamento de Letras Modernas da USP. E-mail: raphael.araujo@usp.br.

2 Doutoranda em literatura francesa junto ao Departamento de Letras Modernas da USP. E-mail: samaralocio@gmail.com. 
seriam publicados (como O Estrangeiro, O verão, O mito de Sísifo, A peste etc.), reações a críticas, passagens poéticas, recortes de momentos históricos, entre outros. A heterogeneidade de tal suporte é tamanha que a crítica consagrada não o situou em um gênero de texto (a exemplo do diário), mas a uma forma de escritura particular ao próprio Camus. O acesso do público a esse material se deu por meio da publicação póstuma em três volumes denominados Carnets, que saíram pela editora Gallimard respectivamente em 1962, 1964 e 1989 e, posteriormente com algumas revisões, nas edições da Pléiade de 2006 e 2008. Embora alguns dos cadernos tenham vindo a público logo após a morte do escritor, pode-se dizer que o momento de maior atenção da crítica a esse material foi em novembro de 2010, quando ocorreu o colóquio "Les Carnets d'Albert Camus. "Écrire, ma joie profonde!", em Angers, celebrando os cinquenta anos de sua morte e que resultou a obra Lire les carnets d'Albert Camus, organizada por Anne Prouteau e Sophie Hébert. Trata-se de uma coletânea de artigos que refletem as múltiplas facetas desse material, que se coloca em um delicado espaço dividido entre laboratório para a criação e lugar performático da escritura, ambos contribuindo para a realização de um estilo próprio:

Des pages quadrillées de simples cahiers d'écolier et d'allure variée accueillent depuis 1935, pêlemêle, dessins, schémas, paragraphes, mots ou phrases isoles, ratures et ajouts. Dès les premiers, Camus va constituer une sorte de champ d'essai perpétuel où se jouera le jeu complexe de la création du texte; la page quadrillée restera pour l'écrivain un espace matériel privilegie. Sitôt lancé, le petit cahier se métamorphose en Cahier avec majuscule; il devient le support, peu à peu, d'un exercice tout à fait personnel. (GAY-CROSIER, 2006, p. 1379)

A frase central que figura na capa dessa obra crítica é "Escrever, minha alegria profunda!", reproduzindo um fragmento que consta nos cadernos para colocá-los em evidência como um espaço de liberdade, lugar em que a possibilidade de escrever se basta a si mesma e se sobrepõe à multiplicidade de funções que se possa atribuir a tal ato. Para o pensamento camusiano, uma "alegria profunda" também reaparece em um movimento de retorno às origens primeiras do homem em comunhão com o mundo. Em outro fragmento do caderno encontramos justamente a alegria de escrever ligada ao prazer encontrado nos banhos de mar: "Eu preciso escrever, como eu preciso nadar, porque o meu corpo exige." ${ }^{13}$ No caso de sua experiência (biográfica, que, no que concerne aos cadernos, acreditamos ter tanta importância quanto as experiências literária e filosófica), trata-se também da relação com a pobreza banhada pelo sol de uma infância junto ao Mediterrâneo, nos bairros periféricos de Argel, que elevou valores centrais na obra do escritor, como o desnudamento e o silêncio.

Tema central na obra camusiana, esse silêncio foi abordado direta e indiretamente pelo cânone de sua crítica. Em uma das principais obras que mencionam o escritor, O grau zero da escritura, Roland Barthes vê o silêncio camusiano como o de uma escritura neutra e transparente; Jean-Paul Sartre, no seu artigo "Explicação do Estrangeiro", faz menção a um mundo sem explicações e aproxima a experiência de leitura de tal obra à observação de um homem que fala dentro de uma cabine de telefone, vemos somente os seus gestos sem que possamos escutá-lo; Maurice Blanchot, em seu célebre artigo "Le retour vers la simplicité", faz referência à tradição da objetividade grega e do niilismo russo que alimentam a escritura camusiana, mas sendo ela, antes de tudo, expressão de uma simplicidade própria à experiência "imediata": "(...) si l'art qu'il aime passe par de beaux noms glorieux, ce qui nourrit son art est dans la vie et sa vie immédiate" (BLANCHOT,

\footnotetext{
3 "Il me faut écrire comme il me faut nager, parce que mon corps l'exige."(CAmus, 2006, p. 811)
} 
1970, p. 106). Enfim, o crítico Hiroshi Mino dedicou uma obra a esse tema, dividindo-o entre o silêncio "biográfico" de Camus, relacionado a um amor transmitido pela mãe doente, semissurda e muda, e a um silêncio primordial, que se remete às origens do homem anteriores à palavra:

Ce silence, c'est d'abord le silence de la mère, ensuite celui de la nature. Ces deux silences, l'un à l'origine de l'histoire personnelle, l'autre à l'origine de l'histoire humaine, ont tous les deux le caractère d'un silence primitif. En d'autre termes, il ne s'agit pas ici du silence qui naît au moment où la parole s'interrompt, mais de celui qui s'étend infiniment avant que la parole ne naisse. (MıNo, 1987, pp. 15-16)

Instaura-se, assim, na escritura camusiana uma tensão entre o desejo de expressar esse silêncio e o único meio que o escritor dispõe para se expressar, as palavras. Podemos relacionar uma nota dos cadernos a essa premente contradição: "Estrangeiro, confessar que tudo me é estrangeiro. Agora que tudo está claro, esperar e nada poupar. Trabalhar pelo menos para perfazer ao mesmo tempo o silêncio e a criação. Todo o resto, todo o resto, seja o que for, é indiferente." ${ }^{4}$ Em sua escritura, Camus funda o que poderíamos nomear "estética do silêncio"; em outra nota dos cadernos podemos observar uma espécie de advertência para si mesmo: "Para escrever, estar sempre um pouco aquém da expressão (muito mais que além). Sem tagarelices em todo caso."

Dessa forma, levando em conta esse silêncio primordial como valor elementar da criação camusiana, presente em sua "alegria profunda", não seria possível, então, ver os cadernos como o lugar primitivo no qual esse mesmo silêncio irá "ecoar"? Visto que esse tema atravessa toda a obra do escritor, ele pode se tornar ferramenta fundamental para projetar uma postura tradutória a esse suporte, uma temática para a tradução de algo tão heterogêneo: "L'acte de se taire décline ou emprunte différentes formes dans Les Carnets (...)" (ProutEAu, 2012, p. 189). Contraditoriamente, o silêncio se faz ouvir pelas palavras do escritor e para preservar seu efeito é necessário recorrer a uma tradução que se prenda à letra, em prol de uma ética que respeite a experiência íntima do texto de partida e a faça transparecer no texto de chegada, postura essa defendida por Antoine Berman em L'épreuve de l'étranger (1984) e La traduction et la lettre (1984), como veremos a seguir.

\section{ANTOINE BERMAN E ALBERT CAMUS: UMA ÉTICA DO SILÊNCIO}

Dentre as diversas especificidades dos cadernos, o fato de se tratar de uma escritura íntima e incompleta exige maior atenção para um trabalho que enfoque o detalhe das anotações cotidianas, muitas vezes descontextualizadas, sem o trabalho final do autor que consagraria uma tentativa de finalizar o processo de criação de sua obra. Mesmo a definição dos cadernos como obra já pode ser problemática, como um primeiro obstáculo à aplicação de uma metodologia que almejasse desprender um sentido em comum entre o que está escrito em francês e a língua de chegada, o português.

É muito provável que Camus tivesse a intenção de publicar seus cadernos, uma vez que ele mesmo datilografa e corrige alguns deles, um processo comum a todos os seus textos publicados. Na última edição dos

4 "Étranger, avouer que tout m'est étranger. Maintenant que tout est net, attendre et ne rien épargner. Travailler du moins de manière à parfaire à la fois le silence et la création. Tout le reste, tout le reste, quoi qu'il advienne, est indifférent." (CAMUs, 2006, p. 906)

5 "Pour écrire, être toujours un peu en deçà dans l'expression (plutôt qu'au delà). Pas de bavardages en tout cas."(CAMus, 2006, p. 856) 


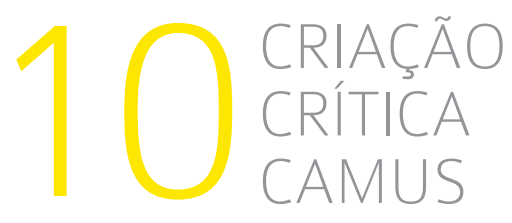

cadernos de Camus, em suas CEuvres complètes, da Pléiade (2006-2008), Raymond Gay-Crosier comenta as intervenções do escritor nos cadernos:

Au début du premier Cahier, il a coupé aux ciseaux ou à la lame de rasoir des pages entières. Par la suite, ses nombreuses interventions sur le manuscrit aussi bien que sur les dactylogrammes prennent toutes les formes possibles, allant de la biffure à l'ajout de longueur variable. (GAY-CROSIER, 2006, p. 1383)

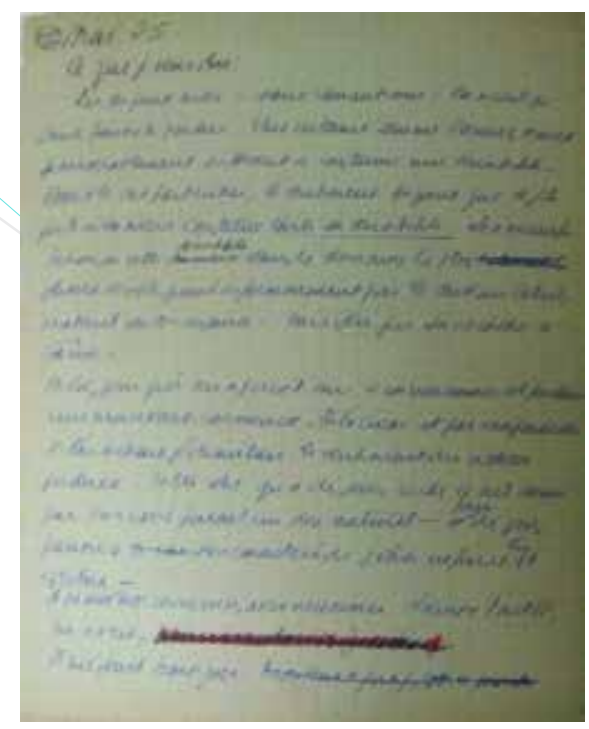

Mas Gay-Crosier vai além deste comentário e demonstra que Camus não conseguiu intervir em todo material que veio à publicação póstuma. A revisão foi realizada por sua filha, Catherine Camus, e teve algumas intervenções da secretária do escritor junto à Gallimard, bem como a inserção de notas que não constavam nos manuscritos ("Dans le V il y a tout un passage ajouté de la main de A. qui ne figure pas sur le manuscrit"). Com isso, ele coloca em evidência o caráter arbitrário de algumas notas e a impossibilidade de se saber até que ponto se fez valer essa intervenção do autor.

Considerando essa primeira ambiguidade no que tange à natureza do suporte, a escolha feita para traduzi-lo visa a dar prioridade à preservação das anotações tal qual estão presentes nos fragmentos, mantendo em alguns momentos sua obscuridade inerente. Esse material era objeto de uma "création corrigée", conforme menciona o escritor no seu IV caderno, um espaço para a liberdade da reescritura que traz à tona a transposição das experiências particulares do autor em um "gênero" que acaba por lhe ser particular. Diante da delimitação do objeto do traduzir, a ética da tradução postula uma "dimensão dialógica" que deve receber a cultura do Outro, visando a preservar o que nele há de original.

Nesse sentido, em A prova do estrangeiro (1984), Berman faz uma arqueologia da tradução no pensamento alemão pelas reflexões do romantismo, mas remontando, em primeiro lugar, ao papel central da tradução que Lutero faz da Bíblia como texto que funda uma cultura literária baseada na relação com o latim e o hebraico. A operação de Verdeutschung (a "alemanização") com o objetivo de trazer o texto da Bíblia para o falar alemão do povo recebe aqui um suplemento que visa a um equilíbrio entre a língua de partida e a de chegada por diferentes modos de traduzir que coloquem em evidência as "aporias fundamentais da tradução e a intuição do que é possível e necessário fazer em um determinado momento histórico" (BERMAN, 2002, pp. 61-62) O seu efeito é indicar que a formação de uma cultura nacional deve passar pela tradução e, portanto, pela relação com o estrangeiro.

Com tal herança, no âmbito do romantismo da segunda metade do século XVIII, Herder irá priorizar uma tradução que preserve a fidelidade do texto, avesso à tradução francesa etnocêntrica consagrada na época, que realiza uma operação "embelezadora" e "poetizante", segundo a qual a tradução ideal seria aquela que conserva o "bom francês" do classicismo, canonizado por clássicos como Molière e Racine. Seria necessário expor a obra com sua estranheza para que se fosse possível um alargamento da cultura de chegada. Assim, a tradução detém papel fundamental para a constituição da Bildung romântica e de uma literatura universal, conforme se verá em Goethe. Da mesma maneira que a personagem de um Bildungsroman, como Wilhelm 
Maister, realiza viagens a outros países, nega suas origens para, com uma nova experiência de percurso (Erfahrung), reafirmá-las, o ato de traduzir se realiza por um desdobramento do sujeito, "pois este parte, com efeito, do próprio, do mesmo (o conhecido, o cotidiano, o familiar), para ir em direção ao estrangeiro, ao outro (o desconhecido, o maravilhoso, o Unheimlich) e, a partir dessas experiências, retornar a seu ponto de partida" (Berman, 2002, p. 84). A língua de chegada é rejuvenescida pelo estrangeiro ao trazer as renovações que a obra literária realizou no original.

A contribuição alemã percorrida por Berman ainda traz diversos elementos que serão constitutivos de uma ética do traduzir, como uma progressão da visão dos românticos da Athenäum presente em F. Schlegel e Novalis - com o movimento do sujeito que transcende a si mesmo, tornando-se consciente do outro ao ponto de multiplicar ao extremo a possibilidade de traduzir a alteridade -, até uma atitude crítica ante a tradução e seu âmbito simbólico, uma hermenêutica que o autor aborda em Humboldt e Schleiermacher, que delimita o que seria a "tradução autêntica" e a "não autêntica". A herança desse programa alemão poderia ser vista no bom resultado de uma tradução legitimamente presa à letra, como faz Hölderin com a Antígona - um trabalho sobre o alemão arcaico da língua de chegada para se buscar uma correspondência com o grego antigo da de partida.

Tal tradução é mencionada em A tradução e a letra ou o albergue do longínquo (1984), juntamente ao trabalho de Chateaubriand feito sobre o poema O paraíso perdido, de John Milton, e a tradução da Eneida, por Klossowski. Nessa obra de menor extensão, Berman sintetiza os valores que guiam a tradução romântica alemã e projeta-os sobre sua tradução da letra, baseada em uma ética de tradução fiel, em uma poética que se atenha à materialidade da palavra e no apego "pensante" ao fenômeno particular de cada operação tradutória, em oposição à postura de Nida, cujo trabalho de tradução seria uma extensão do projeto imperialista americano de anexação do estrangeiro.

Em outras palavras, essa postura visa a mitigar a ideia de uma "equivalência dinâmica" e escapar a "tendências deformadoras" que as traduções hipertextuais, etnocêntricas e platônicas realizam ao buscar traduzir um sentido comum às línguas. Berman realiza uma "analítica da tradução" e elenca treze tendências negativas, dentre as quais a clarificação, enobrecimento, o alongamento, a racionalização etc., para defender uma tradução que não busque "resolver ambiguidades" da obra original, mas compartilhá-las na tradução: "Emendar as estranhezas de uma obra para facilitar sua leitura acaba por desfigurá-la, e, portanto, enganar o leitor a quem se pretende servir. Precisa-se, antes, como no caso da ciência, de uma educação à estranheza." (BERMAN, 2007, p.66)

Dessa forma, considerando um breve sobrevoo sobre questões das duas obras mencionadas, uma tradução ética para Berman seria aquela que promove o encontro ao outro em um espaço de mestiçagem que respeitaria a opacidade das alteridades em confronto. Assim, conforme demonstra Maria Chanut, tradutora de A prova do estrangeiro (2002) para o português do Brasil, o texto traduzido seria o local de uma hospitalidade:

A constante busca do equilíbrio em meio à diversidade só seria possível a partir de uma consciência da transformação e, por essa razão, a linguagem do "novo original" é frequentemente híbrida, ao mesmo tempo impura e enriquecedora. Uma tradução "responsável" pode ser considerada "ética" na medida em que é hospitaleira, ou seja, acolhe o outro por meio do diálogo, da exposição da estranheza, da relação com o outro." (CHANUT, 2012, pp. 168-169) 
Relembrando as reflexões de Derrida sobre o "paradoxo da hospitalidade", Chanut define tal espaço ético da tradução como lugar de onde é possível ouvir duas vozes que coexistem em (des)harmonia. Uma obra traduzida deve evocar não só o que consta no original, mas ainda as tensões do seu processo de criação. Em confluência com tal ideia, a Tradutologia de Berman propõe uma viagem ao tradutor para que, ao percorrer o mundo do Outro, adquira, por um movimento dialético, um olhar modificado sobre sua cultura. Mas Berman também se preocupa com a condição "ancilar" do tradutor ante uma obra ambivalente, que o convida para traduzi-la ao mesmo tempo em que o rechaça: "toda cultura resiste à tradução mesmo que necessite essencialmente dela" (BERMAn, 2002, p. 16). Embora ele postule a valorização de uma tradução da letra, vale destacar que ela deve ser compreendida como a consideração do contexto que criou determinada obra, bem como o de sua tradução. Com o dever de servir a dois senhores, o tradutor deve ter atenção para não cometer excessos de naturalização, traindo o original, nem excessos de estranhezas que tornariam a obra ininteligível.

Quando voltamos a considerar a tradução dos cadernos de Camus, acreditamos que uma ética que preservaria a letra íntima do original deveria, como sugere Berman na segunda obra mencionada, evitar processos como clarificação, racionalização e enobrecimento do texto de partida, visto que em muitas passagens ele não é claro, linear ou elevado - uma vez que se trata de notas cotidianas. Não obstante, seria relevante refletir sobre a ética da tradução de Camus no contexto brasileiro, que tem como principal tradutora do escritor, Valerie Rumjanek e, ao longo da sua história, contou com a participação ilustre e polêmica de Graciliano Ramos na tradução de $A$ peste ${ }^{6}$.

Cabe ainda sublinhar que houve uma tradução portuguesa dos cadernos, que saiu sob o título Primeiros cadernos pela editora Livros do Brasil. A tradução de 1965, realizada por Jánio Quadros, se projetou sobre os seis primeiros cadernos do autor, oferecendo ao leitor lusófono uma primeira oportunidade de acesso a esse material traduzido: "Dir-se-ia assistirmos, em Primeiros Cadernos, à gênese de uma criação literária de invulgar grandeza, tal como veio depois a afirmar-se em inesquecíveis realizações." ${ }^{7}$. Também contribuiu para a tomada de decisões como base para uma retradução em alguns momentos do trabalho ao longo dos fragmentos.

Contudo, ao cotejar o trabalho com a edição original em francês, deparamo-nos com algumas falhas na tradução, desde questões mais simples, como a passagem do termo pastèque para "melancolia", em vez de "melancia", até a presença de algumas lacunas entre fragmentos, como o que ocorre nas notas de fevereiro para março de 1939, quando o tradutor passa do fragmento "La mort de Caporal. Cf. papier" para o fragmento que se inicia por "La mort dans la tragédie...", ignorando a frase "Le fou dans la librairie. Cf. papier." . Isso se repetiu algumas vezes e contou ainda com alterações quanto às ordens dos fragmentos, não respeitando o original.

Mas uma crítica mais aprofundada das obras em português que dialogam com nossa tradução seria um passo além deste texto, que deixamos para um trabalho futuro. O que se pode adiantar é que, sabendo que os cadernos se constituem como plano de fundo para as demais obras de Camus, a intertextualidade com o material traduzido para o português torna-se fundamental na busca por uma ética da letra camusiana, como veremos a seguir ${ }^{10}$.

6 Para tal discussão, o leitor interessado deverá consultar a dissertação de mestrado de Ana Maria Bicalho, sob o título Graciliano Ramos, Valerie Rumjanek e o processo de (re)criação em La Peste, de Albert Camus.

7 Contracapa.

8 Comparar página 124 dessa mesma edição francesa com a página 97 da edição portuguesa.

9 Comparar página 147 da edição francesa de 1962 com as páginas 114 e 115 da edição portuguesa.

${ }^{10}$ As traduções apresentadas limitaram-se aos três primeiros cadernos do escritor, que saíram pela Gallimard em conjunto sob o nome de Carnets, em 1962. Baseamo-nos nessa subdivisão, mas comparamos a edição com a lançada em 2006 junto à Pléiade, 


\section{0}

\section{ESBOÇOS DE TRADUÇÃO DA LETRA}

\subsection{VOZES DE AUTORES E VOZES DE TRADUTORES}

Uma polifonia transparece nas diversas citações de autores lidos pelo escritor e reproduzidos em seus cadernos. Para traduzi-los, faz-se necessário, em alguns casos, recorrer à fórmula consagrada no português brasileiro, como na célebre citação de Nietzsche que Camus reproduz em uma de suas notas, "Un Prométhée - comme idéal révolutionnaire. 'Ce qui ne me fait pas mourir me rend plus fort' (Nietzsche)" (CAmus, 2006, p. 889), que traduzimos como "Um Prometeu como ideal revolucionário - O que não me mata me fortalece." Poderia se alegar que, com essa escolha, estivéssemos realizando uma operação hipertextual, repelida por Berman, mas vale verificar que se trata de uma tradução de um autor, cujo original está em alemão, que foi recortada e inserida nas notas de Camus - não de reprodução original ao seu próprio estilo.

Em outros, quando não há uma estrutura conhecida pelo público, é possível optar por uma nova tradução ou verificar se há reaparecimento de tal trecho na obra traduzida do escritor para o português e, diante disso, refletir sobre as decisões operatórias. Vemos isso na epígrafe de $O$ mito de Sísifo (1942), que aparece nos cadernos em uma nota de fevereiro de 1940: "Ô mon âme, n’aspire pas à la vie immortelle mais épuise le champ du possible" (Pindare - $3^{0}$ Pythique) (CAmus, 2006, p. 995). Nesse caso também é possível recorrer à tradução em português realizada por Ari Roitman e Paulina Watch e publicada pela Record: "Oh, minh'alma, não aspira à vida imortal, mas esgota o campo do possível” (Píndaro - $3^{0}$ Pítico) (CAmus, 2008, p. 15).

Também podemos mencionar o exemplo de outra nota em que Camus reproduz a frase de Poittevin, amigo de Flaubert: "La mort de Le Poittevin, l'ami de Flaubert. 'Fermez la fenêtre ! C'est trop beau."' (CAmus, 2006, p. 894) O qual poderíamos traduzir como: "A morte de Le Poittevin, amigo de Flaubert. 'Fechem a janela! É belo demais.", decisão que pode ser corroborada ao vermos essa passagem no início do ensaio "A pedra de Ariadne", presente na obra O verão (1954), traduzida por Vera Queiroz da Costa e Silva: "Os oraneses parecem assemelhar-se àquele amigo de Flaubert que no instante da morte, lançando um último olhar sobre a terra insubstituível exclamava: 'Fechem a janela! É belo demais!'” (CAmus, 1985, p. 74)

Em outros casos, é possível propor um trabalho com algumas nuances que diferem da tradução consagrada, como em uma nota em que Camus descreve peculiaridades da cidade de Orã e que traduzimos da seguinte forma:

Orã. Cidade (...) na qual se pode ainda encontrar excêntricos cafés com o balcão envernizado de sujeira e salpicado por patas e asas de moscas, onde somos servidos em copos trincados. Felizes cafés de um feliz país onde o cafezinho custa 12 tostões e o grande $18 .{ }^{11}$

Posteriormente, ela aparece de outra forma em uma nota de $O$ verão, que foi assim traduzida para o português na edição de 1985:

com o intuito de evitar possíveis atualizações do texto de uma edição para a outra.

11 "Oran . Ville extravagante (...) où l'on peut encore trouver d'extraordinaires cafés, au comptoir verni de crasse et saupoudré de pattes et d'ailes de mouches, où l'on vous sert dans des verres ébréchés. Heureux cafés d'un heureux pays où le petit café coûte 12 sous et le grand 18." (Camus, 2006, p. 898) 
"Pode se encontrar em Orã:

1. Bares cujo balcão é envernizado de imundície, salpicado de patas e asas de moscas, e onde o dono está sempre sorrindo, apesar da sala sempre deserta. O "cafezinho" custava nesses lugares doze tostões, e o duplo, dezoito." (CAmus, 1985, p. 56)

Embora os trechos sejam semelhantes, buscou-se na nota dos cadernos manter a palavra "café" como lugar em vez da opção "bar" com o intuito de se aproximar mais do original, assim como o adjetivo "grande" em vez de "duplo". Há poucas alterações ante o trabalho consagrado no trecho demonstrado, mas esse é o espaço exíguo em que a intervenção do tradutor se faz perceber na tradução dos cadernos quando há um trabalho prévio e apto à retradução. Trata-se de uma operação distinta da que realizamos ante um fragmento inédito no Brasil, o que ocorre a seguir.

\subsection{A OCASIÃO FAZ O ESTILO - E O TRADUTOR}

Além da diversidade das vozes do próprio Camus em diferentes fases da sua vida, também nos deparamos com diferentes estruturas formais, que se dividem nos diversos "subgêneros" já mencionados na primeira parte deste texto. Selecionamos aqui um caso extremo nas notas de novembro de 1939, quando Camus está viajando de trem pela Argélia, entre Argel e Orã, passa pela cidade de Tlétat, planície ao sudeste de Orã, e escreve uma pequena "oração" para a padroeira da cidade, Santa Bárbara:

... Santa Bárbara do Tlélat, vós que sois indiferença, equivalência e disponibilidade, protegei-nos das escolhas precipitadas demais e deixai-nos essa liberdade sem partilha que tem o nome de desnudamento. Em alguns minutos, será a vez de Orã, o peso de uma vida carnal e sem esperança. Santa-Cruz imóvel e o cheiro de anis nas ruas de Mers-el-Kebir. Será a vez das "Vieilles Cures" que o Café Cintra serve com gelo moído, - as oranesas cujos tornozelos são um tanto grossos e que passam sempre com a cabeça descoberta. Santa Bárbara, preservai as oranesas até o limiar da sua velhice e as renovai, então, por muitas oranesas parecidas que passearão também sob as árvores da velha prefeitura. Impedi, Santa Bárbara, as oranesas de pensar em Argel e em Paris e ensinai-Ihes a verdade desse mundo que é de nada ter. Vós que sois como um cais onde se fuma um cigarro sonhando, esperando um assobio que vos relançará às paisagens da terra, vós sabeis que normalmente não sou religioso. Mas se me acontecer de o ser, vós sabeis que não tenho necessidade de Deus e que só posso ser religioso no momento em que quiser brincar de sê-lo, porque um trem vai partir e minha oração não terá futuro. Santa Bárbara, vós que sois um ponto no espaço na linha Orã-Argel, vós tão carnal e tão precisa, tão terrestre e tão cardinal, sede por alguns segundos a santa de um descrente e a conselheira de um inocente. ${ }^{12}$ (grifos nossos)

12 “... Sainte Barbe du Tlélat, vous qui êtes indifférence, équivalence et disponibilité, gardez-nous des choix trop précipités et laisseznous cette liberté sans partage qui a nom le dénuement. Dans quelques minutes, ce sera Oran, le poids d'une vie charnelle et sans espoir. Santa-Cruz immobile et l'odeur d'anisette dans les rues de Mers-el-Kebir. Ce sera les «Vieilles Cures » que le café Cintra sert dans la glace pilée, - les Oranaises dont les chevilles sont un peu épaisses et qui vont toujours tête nue. Sainte Barbe, préservez les Oranaises jusqu'au seuil de leur vieillesse et remplacez-les alors par beaucoup de pareilles Oranaises qui se promèneront aussi sous les arbres de la vieille préfecture. Empêchez, sainte Barbe, les Oranaises de penser à Alger et à Paris et enseignez-leur la vérité de ce monde qui est de n'en point avoir. Vous qui êtes comme un quai où l'on fume une cigarette en rêvant, en attendant un coup 
Em primeiro lugar, vale destacar a escolha feita no momento da tradução, que foi de manter o pronome "vous" do francês para o "vós" do português, o que aproxima o discurso de uma prece religiosa católica, como o conhecido Pai-Nosso. Isso potencializa a "brincadeira" do escritor descrente, que funde o discurso religioso a valores pagãos e terrestres, como o olhar da santa enquanto "indiferente", "terrestre" e "carnal", a adjetivação da perna das oranesas e a sua "renovação" terrestre.

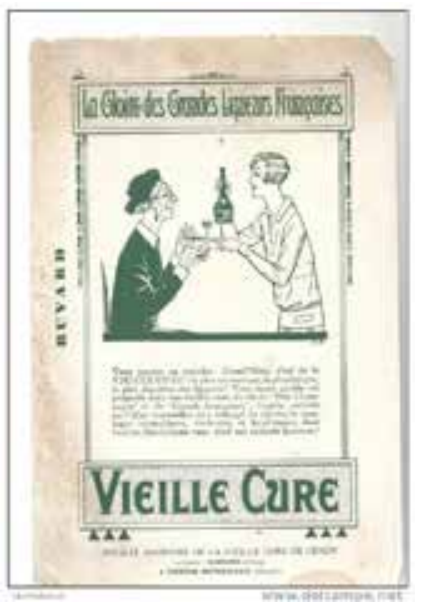

Outro ponto a se ressaltar é a escolha de manter o nome próprio da bebida de "Vieilles Cures" como consta no original e acrescentar a palavra "licor" ao lado por tratar-se de um licor tradicional francês da região de Bordeaux. Na tradução, esse acréscimo teria o objetivo de dar materialidade à bebida, possibilitar que o leitor saiba tratar-se de álcool ao mesmo tempo em que o aperitivo se mantém particular ao gosto de Camus - não se trata de qualquer licor, mas das "Vieilles Cures", tão tradicional à época que figura em propagandas disponíveis até hoje na internet.

Poderia se dizer que a intervenção de um termo seria prejudicial à preservação do suporte tal qual o escritor o deixou, contudo, priorizou-se aqui uma tentativa de aproximar experiência de Camus ao leitor brasileiro. Essas particularidades inerentes aos cadernos que convencionamos chamar aqui por polifonias remete a tradução a uma operação que está longe de se limitar a uma transposição da letra do francês para o português. Tentou-se, antes, dar o devido cuidado à singularidade de cada fragmento em vias de manter um equilíbrio a um texto que seja acessível ao leitor e que preserve os aspectos não só da cultura de partida, mas da experiência do próprio escritor.

\subsection{AS TENSÕES DO SILÊNCIO: PRESCRIÇÕES DO MÉTIER D'ÉCRIVAIN}

Outra particularidade dos cadernos que deve ser observada ocorre nas anotações em que o escritor estabelece regras para se impor um silêncio fundamental à criação. Diferentemente do diário tradicional cujo proprietário deve relatar suas experiências cotidianas, os Carnets são repletos de "medidas prescritivas" para o comportamento ideal de um artista que deseja compor grandes obras em busca da verdade, como demonstra Prouteau: "L'émergence de l'artiste est conjointe à l'émergence de l'homme. De nombreux fragments des Carnets associent à ce travail artistique une quête intérieure faite d'oubli de soi, de renoncement, de recherche de vérité." (Prouteau, 2012, p. 193) Criar exige dedicação, desnudamento, renúncia e, principalmente", silêncio:

Abril de 38.

O que há de sórdido e de miserável na condição de um homem trabalhando e em uma civilização fundada sobre homens trabalhando.

de sifflet qui vous relancera vers les paysages de la terre, vous savez que je ne suis pas souvent religieux. Mais s'il m'arrive de l'être, vous savez que je n'ai pas besoin de Dieu et que je ne puis l'être qu'au moment où je veux jouer à l'être, parce qu'un train va partir et que ma prière sera sans lendemain. Sainte Barbe, vous qui êtes un point dans l'espace sur la ligne Oran-Alger, plus près d'Oran, très près d'Oran, et un arrêt dans le temps qui m'achemine vers Oran, vous si charnelle et si précise, si terrestre et cardinale, soyez pour quelques secondes la sainte d'un incroyant et la conseillère d'un innocent." (Camus, 2006, pp. 897-898) 
Mas trata-se de resistir e não recuar. A reação natural é sempre de se dispersar do trabalho, criar ao redor de si admirações banais, um público, um pretexto para covardia e a comédia (a maioria dos refúgios é criada para isso). Outra reação inevitável é fazer frases. Aliás, isso pode ir bem se juntarmos aí uma desenvoltura física, a não aplicação ao corpo e a frouxidão da vontade. Trata-se primeiro de se calar - de suprimir o público e de saber se julgar. De equilibrar um aplicado cultivo do corpo com uma aplicada consciência de viver. De abandonar toda pretensão e se dedicar a um duplo trabalho de liberação: - sob o aspecto do dinheiro e de suas próprias vaidades e covardias. Viver sob regras. Dois anos não são demais em uma vida para refletir sobre um só ponto. É preciso liquidar todos os estados anteriores e colocar primeiramente toda a sua energia em nada desaprender, em seguida a pacientemente aprender.

Com este esforço há uma chance em dez de se escapar da mais sórdida e mais miserável das condições: a do homem que trabalha. ${ }^{13}$

No trecho em questão, como a já mencionada tentativa de reproduzir o silêncio camusiano, buscou-se uma aproximação à letra original pela reprodução de estruturas francesas no texto em português. Para tanto, recorreu-se, em alguns casos, à preservação de inversões sintáticas, como na posição do adjetivo em attentive culture du corps/aplicado cultivo do corpo e attentive consciensce de vivre/aplicada consciência de viver; na posição do objeto em rien desapprendre/nada desaprender; e com a posição do advérbio em ça peut d'ailleurs./isso pode aliás.

Não obstante, buscou-se uma aproximação formal também em algumas lexias como s'attacher/se ater; seul/só; prix-là/esse preço; hommes travaillant/homens trabalhando (a forma mais próxima seria "homens trabalhantes", mas a neologia não seria tão essencial nesse fragmento); faire des frases/fazer frases/ e relachement de la volonté/afrouxamento da vontade (sendo que se preferiu "afrouxamento" a "relaxamento", dadas as outras conotações que esse último termo poderia evocar).

Há, contudo, trechos em que tal aproximação não foi possível, pois inviabilizaria a composição de um texto coerente em português, o que nos levou a traduzir "Vivre en règle" por "Viver conforme a regra", "des admirations faciles" por "estimas banais", "coller ensemble" (literalmente "colar junto") por "combinar bem", entre outros. Essa busca por um equilíbrio teve como norteador o estabelecimento de um espaço entre línguas que mantivesse a "tensão" inerente a notas em que o escritor também está à procura do seu equilíbrio

13 "Avril 38

Ce qu'il y a de sordide et de misérable dans la condition d'un homme travaillant et dans une civilisation fondée sur des hommes travaillant. Mais il s'agit de tenir et de ne pas lâcher prise. La réaction naturelle est toujours de se disperser hors du travail, de créer autour de soi des admirations faciles, un public, un prétexte à lâchetés et comédies (la plupart des foyers sont créés pour ça). Une autre réaction inévitable est de faire des phrases. Ça peut d'ailleurs coller ensemble, si on y ajoute le laisser-aller physique, l'inculture du corps et le relâchement de la volonté.

II s'agit d'abord de se taire - de supprimer le public et de savoir se juger. D'équilibrer une attentive culture du corps avec une attentive conscience de vivre. D'abandonner toute prétention et de s'attacher à un double travail de libération - à l'égard de l'argent et à l'égard de ses propres vanités et de ses lâchetés. Vivre en règle. Deux ans ne sont pas de trop dans une vie pour réfléchir sur un seul point. Il faut liquider tous les états antérieurs et mettre toute sa force d’abord à ne rien désapprendre, ensuite à patiemment apprendre. À ce prix-là, il y a une chance sur dix d'échapper à la plus sordide et la plus misérable des conditions : celle de l'homme qui travaille." (CAmus, 2006, pp. 849-850) 
interior: "(...) ce sont des combats intérieurs qui se jouent à tous les âges de son parcours et gagnent en intensité au fur et à mesure des années." (Prouteau, 2012, p. 188)

Se Berman ressalta que as obras artísticas publicadas são detentoras de um combate com a linguagem que já evoca a intraduzibilidade, o que dizer dos cadernos nos quais essa luta é uma constante não só no estilo, mas também em sua temática, colocando tal suporte em uma posição de objeto de criação e de metalinguagem? O fragmento de abril de 1940 não expõe uma gênese de uma obra específica, mas uma fase fundamental na gestação que compreende os valores de um escritor e o significado do criar artístico - o momento pré-silêncio. Se a obra ideal de Camus não nasceu dois anos depois, duas apareceriam em quatro: O estrangeiro e O mito de Sísifo, publicados em 1942 para abalar a história da literatura e da filosofia francesa do século XX.

\section{A TRADUÇÃO COMO MOVIMENTO CRÍTICO}

Os fragmentos traduzidos dialogam com a tradução da letra de Berman em níveis diferentes, dentre as quais, apenas três foram aqui expostos. Primeiramente, foi proposta a relação com algumas traduções brasileiras e a única tradução dos cadernos para o português de Portugal, enquanto movimento reflexivo sobre a função autor de Camus que, segundo Foucault ${ }^{14}$, atribui unidade a uma série de textos - e, no nosso caso, de traduções. Em seguida, as experiências eventuais dos cadernos e seu efeito de modificar algo na linguagem do escritor, como no caso da estrutura da prece, também foi objeto de uma breve análise. Enfim, as próprias tensões do ato de escrever surgem na metalinguagem do escritor em busca do silêncio ideal de sua obra, o mesmo silêncio do qual a tradução busca se aproximar pela mestiçagem estrutural como meio de equilíbrio entre a língua de partida e a de chegada, mesmo sabendo que "O defeito da tradução é inerente à tradução" (BERMAN, 2007, p. 134).

Respeitar o mosaico de regras e de estilos que os cadernos renovam a cada fragmento é, portanto, ler os conceitos de Berman sem tomar como norma imprescindível suas críticas, como as "tendências deformadoras" e a "tradução hipertextual". Deve-se considerá-las antes como ponto de partida, como gesto possível e consciente do tradutor diante de cada fenômeno. A necessidade de reflexão sobre a postura do tradutor oferece uma reaprendizagem do ato de traduzir, pois embora se aplique uma metodologia durante o processo, que envolva a seleção de um corpus específico ao autor, uma auctoritas sobre sua obra e um recorte teórico que mais se aproxime do suporte, a heterogeneidade dos cadernos evoca a versatilidade e a flexibilidade para lidar com um objeto que é, sobretudo, fruto de uma experiência íntima do ato de escrever.

Trata-se também de esboçar uma "crítica da tradução" presa à experiência que envolve cada operação, como Berman defende em sua última obra sobre John Donne, na qual repensa a infrutífera negatividade da crítica que se limita a julgar traduções, ignorando os contextos que as produziram: "Analyser une traduction sans remonter au système de normes qui l'a modelée, puis la 'juger' sur cette base, est donc une opération absurde, et injuste, puisqu'elle ne pouvait pas être autrement, et qu'elle n'avait sens comme acte de traduction que comme opération assujettie à ces normes" (BERMAN, 1995, p. 53).

Sendo 2013 o ano do centenário de Albert Camus, data que leva sua crítica pelo mundo a repensar o valor de sua obra, cabe refletir também no Brasil, "terra da desmedida"15, sobre a hospitalidade com a qual

\footnotetext{
14 Em seu célebre texto "O que é um autor?".

${ }^{15}$ Camus chama o Brasil de "terra da desmedida" em suas anotações de viagem de 1949, que também integram os Carnets.
} 


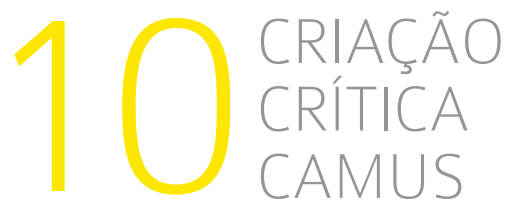

se tem recebido os textos do autor. Arriscar-se pela tradução dos cadernos está longe de oferecer todas as respostas para tal problemática, mas pode servir como um ponto de partida para trazer, novamente, as palavras desse escritor aos leitores brasileiros abertos à crítica e à prova do estrangeiro.

\section{REFERÊNCIAS BIBLIOGRÁFICAS}

Barthes, Roland. O grau zero da escritura. São Paulo: Cultrix, 1971.

Berman, Antoine. A prova do estrangeiro. Bauru, SP: Edusc, 2002.

A tradução e a letra ou O albergue do longínquo. Rio de Janeiro: 7Letras/PGET, 2007.

Pour une critique des traductions: John Donne. Paris: Éditions Gallimard, 1995.

BlANCHOT, Maurice. "Le retour vers la simplicité". In: La critique de Camus et notre temps. Paris: Gallimard, 1970.

Camus, Albert. Le Mythe de Sisyphe. Paris : Gallimard, 1965.

. CEuvres complètes. Tomes I et II. Paris: Gallimard, 2006.

OEuvres completes. Tomes III et IV. Paris: Gallimard, 2008.

O mito de Sísifo. Tradução de Ari Roitman e Paulina Watch Rio de Janeiro: Record, 2008.

Livro, 1985.

. Núpcias, O verão. Tradução de Vera Queiroz da Costa e Silva. São Paulo: Círculo do

Camus, Cathérine Albert Camus solitaire et solitaire Paris: Michel Lafon, 2010. Imagens dos Cadernos de Albert Camus.

Chanut, Maria Emília Pereira. "A tradução ética em A prova do Estrangeiro". Revista Criação \& Crítica, n. 9, p. 161-173, Nov. 2012. Disponível em: 〈http://www.revistas.usp.br/criacaoecritica〉. Acesso em 12/12/2012.

Gay-Crosier. "Carnets (Mai 1935-décembre 1948) Notice". In: Camus, Albert. OEuvres complètes. Tomes I et II. Paris: Gallimard, 2006.

Geske, Samara F. A. O. Lócio. O avesso e o direito da escritura camusiana. De écrits de jeunesse a L'étranger. 2011. Dissertação de Mestrado. 129 f. São Paulo: Universidade de São Paulo, 2011.

Mıno, Hiroshi. Le silence dans l'œuvre d'Albert Camus. Paris: J. Corti, 1987.

Prouteau, Anne. \& Spiquel, Agnes. Lire les Carnets d'Albert Camus. Villeneuve d'Ascq: Presses Universitaires du Septentrion, 2012.

Prouteau, Anne. "Se taire. Écouter. Laisser déborder: le travail de l'écrivain ! Lire les Carnets d'Albert Camus. Villeneuve d’Ascq: Presses Universitaires du Septentrion, 2012.

ARTIGO RECEBIDO EM: 31 jan. 2013.

ARTIGO ACEITO EM: 20 abr 2013.

REFERÊNCIA ELETRÔnICA: Araúso, Raphael luiz de \& GeSkE, Samara Fernanda A. O. de Lócio e Silva. O silêncio do Estrangeiro: por uma tentativa da tradução da letra nos primeiros cadernos de Albert Camus. Revista Criação \& Crítica, n. 10, p. 107-118, maio 2013. Disponível em: 〈http://www.revistas.usp.br/criacaoecritica〉. Acesso em dd mmm aaaa. 